\title{
POLÍTICA E LINGUAGEM EM ROUSSEAU E CONDILLAC ${ }^{I}$
}

\author{
Evaldo Becker" \\ evaldobecker@gmail.com
}

RESUMO Nosso objetivo no presente artigo é apresentar alguns elementos referentes ao debate acerca da origem e função da linguagem, ocorrido, principalmente, a partir do $4^{\circ}$ e $5^{\circ}$ decênios do século XVIII, entre Rousseau e Condillac. Pretendemos expor as principais similitudes e divergências que podem ser verificadas entres os escritos dos dois autores, prioritariamente no que concerne às relações estabelecidas por estes entre a linguagem e a política. Ressaltamos que o principal texto de Condillac a ser analisado é o Essai sur l'origines des connaissances humaines, obra publicada em 1746, e que Rousseau, na primeira parte do Discurs sur l'origine et les fondemens de l'inégalité parmi les hommes, admite ter sido a fonte de suas primeiras ideias acerca da questão da origem das línguas. Quanto aos escritos de Rousseau, ressaltamos que nossa análise centrar-se-à, sobretudo, no Discours sur l'inégalité e no Essai sur l'origine des langues.

Palavras-Chave Rousseau, Condillac, politica, linguagem.

ABSTRACT My aim in this paper is to present some aspects of the debate which Rousseau and Condillac had concerning the origins and functions of language - a debate originating for the most part in the 4th

1 Uma primeira versão, bastante reduzida, do presente artigo foi publicada sob o título „Origem e função da linguagem em Rousseau e Condillac" nos Anais do IV Colóquio Rousseau - Rousseau: Filosofia, literatura e educação, Londrina, 2009 - ISSN: 2176-2554 (Versão digital - CD).

* Pós-doutor em Filosofia pela USP. Professor do Departamento de Filosofia da UFS. Pesquisador do Núcleo de Estudos e Pesquisas em Filosofia da História e Modernidade - NEPHEM. Artigo recebido em $5 / 08 / 2010$ e aprovado em 28/01/2011.

KRITERION, Belo Horizonte, nº 123, Jun./2011, p. 49-74. 
and 5th decades of the eighteenth century. I intend to single out the main similarities and divergencies seen in the writings of those two authors, with especial regard to the relations established by them between language and politics. It should be noted that the main text by Condillac under analysis here is the Essai sur l'origines connaissances humaines, published in 1746, which Rousseau, writing in the Discurs sur l'origine et le fondement des inegalités parmi les hommes, acknowledges as the source of his first thoughts on the question of the origin of languages. As for Rousseau's writings, it should be stressed that my analysis focuses, above all, on the Discurs sur l'inegalité and the Essai sur l'origine des langues.

Keywords Rousseau, Condillac, politics, language.

A relação de Rousseau com Condillac foi, desde o início, bastante amistosa, apesar das divergências teóricas que podem ser percebidas entre os dois. Tais divergências, que se dão sobretudo no que diz respeito à origem e função da linguagem, nunca teve nada de traumático, diferentemente do que se deu com Diderot, Grimm e os demais enciclopedistas. Tal fato pode ser explicado, talvez, em função do temperamento do abade, bastante circunspeto e pouco afeito a contendas. Rousseau descreve no capítulo sete das Confissões algumas passagens desta relação de amizade e de convívio filosófico numa época em que tanto ele quanto Condillac gozavam ainda de um tranquilo anonimato. Vejamos nas próprias palavras do autor, a descrição retrospectiva do período em questão:

Ligara-me também com o abade de Condillac, que, como eu, nada era então na literatura, mas que estava marcado para se tornar o que é hoje. Fui eu o primeiro, talvez, que lhe conheci as capacidades e as estimei no que valiam. Ele também parecia que gostava da minha companhia, e quando, trancado no meu quarto da rua Jean Saint-Denis, eu trabalhava no meu ato de Hesíodo, ele às vezes vinha jantar comigo, só nós dois em piquenique. Trabalhava ele então num 'Ensaio Sobre a Origem dos Conhecimentos do Homem' que é a sua primeira obra”. ${ }^{2}$

Após a descrição que retrata os momentos iniciais da relação entre os filósofos, Rousseau menciona ainda o fato de ter sido ele o responsável 
indireto pela publicação do Essai de Condillac, dado o fato de ter apresentado o abade à Diderot na intenção de encontrar um editor para o livro, após este ter sido terminado. Foi justamente em função do Essai de Condillac que teve início suas discussões acerca da origem e função da linguagem.

Se observarmos o verbete Linguagem, presente no Dictionnaire de Rousseau, veremos que "as concepções linguísticas" do cidadão de Genebra são tratadas essencialmente ${ }^{3}$ nestas três obras: O segundo Discurso, o Ensaio sobre a origem das línguas e no Emílio ${ }^{4}$. Em todas elas podemos perceber traços marcantes da presença das ideias Condillaquianas.

Contudo, mesmo afirmando ter sido O Essai de Condillac a primeira fonte de suas ideias acerca da origem e dos progressos da linguagem, Rousseau não deixa de assinalar as profundas divergências percebidas entre suas concepções. Ele insiste sobre as dificuldades inerentes às pesquisas em questão e esmiúça em detalhe os momentos iniciais desta Instituição humana fundamental que é a linguagem, responsável em última instância, pelos progressos, pelas mazelas e, talvez, pelas fracas possibilidades de redução do mal-estar vivenciado pelo homem em sociedade.

Ainda na primeira parte do segundo Discurso, após ter tratado das descrições do homem natural, sob o ponto de vista de sua constituição física, Rousseau analisa o homem, sob o ponto de vista de sua constituição 'metafísica ou moral'. ${ }^{5}$ Para tanto ele passa a investigar as condições em que se deram os primeiros progressos do espírito humano e as faculdades necessárias para que se desencadeasse tal processo. Após admitir-em conformidade com Condillac ${ }^{6}$ e em contrariedade com Buffon ${ }^{7}$ - que mesmo os animais possuem um certo

3 Essencialmente, mas não exclusivamente. Conforme mostramos no primeiro capítulo, da tese intitulada Política e Linguagem e Rousseau, o interesse de Rousseau pelas questões relacionadas ao uso público ou político da linguagem, bem como sua relação com os costumes dos povos evidencia-se muito antes de virem à luz seus escritos mais importantes. Exemplo disso pode ser visto no fragmento sobre a eloquência que data provavelmente de 1735. Além disso, cabe ressaltar a importância da crítica realizada por Rousseau na Nova Heloísa, no que concerne ao tipo de linguagem empregada nos salões e nos teatros; linguagem esta 'própria para os sussurros dos sofás' e pouco digna de uma verdadeira vida política exercida em termos republicanos. Para além desses exemplos mais evidentes poderíamos citar outras ocorrências pontuais, mas que não invalidam a tese exposta no Dictionnaire de Rousseau, apenas servem para nuançá-las. Cf. BECKER, Evaldo. Política e Linguagem em Rousseau. Tese de doutorado realizada sob a orientação do Prof. Dr. Milton Meira do Nascimento, defendida em Junho de 2008 na USPUniversidade de São Paulo.

4 Dictionnaire de Rosseau. Publié sous la direction de Raymond Trousson et Frédéric S. Eigeldinger. Honoré Champion Editeur, Paris : 2006, p. 618.

5 ROUSSEAU, O.C. III, Discours sur l'inégalité, p. 141.

6 Cf. Goldschmidt: "Après avoir accordé à Condillac que l'entendement ne saurait servir à distinguer l'homme et l'animal, Rousseau va montrer que l'entendement est un critère, et un critère décisif, pour distinguer l'homme civilisé et l'homme naturel ». GOLDSCHMIDT : 1983, p. 293-4.

7 Sobre a polêmica acerca da temática relacionada à existência ou não de graus de entendimento por parte dos animais é importante ler o 'Traité des animaux' de Condillac onde este confronta as posturas 
grau de entendimento e que a diferença com relação ao entendimento humano é apenas de proporção, Rousseau dedica-se a reconstituir a história hipotética da linguagem e da sociedade a partir das faculdades características do homem, tais como a liberdade, a piedade (pitié) e a perfectibilidade . Faculdades estas que possibilitam à espécie humana a superação do próprio instinto, que até então a governava, e através do estabelecimento da comunicação, permitem sua saída deste estado de animalidade e de estupidez, ${ }^{8}$ no qual pouco se diferencia das demais bestas; possibilitando assim, a entrada em uma nova fase de sua história ${ }^{9}$.

Rousseau insiste nas dificuldades e nos entraves que marcam essa passagem e aponta para a ausência de comunicação como sendo a principal responsável pela estagnação da espécie humana.

Que se imagine quantas ideias devemos ao uso da palavra; o quanto a gramática exerce e facilita as operações do espírito, que se pense nos trabalhos inconcebíveis e no tempo infinito que deve haver custado a primeira invenção das línguas; que se acrescentem essas reflexões às precedentes e se calculará quantos séculos foram necessários para desenvolver sucessivamente no espírito humano as operações de que era capaz. ${ }^{10}$

Além da passagem acima, outras confirmam a ideia segundo a qual houve um longo período no qual a espécie humana, espalhada em meio a natureza, pouco progrediu. E tal fato, conforme Rousseau insistirá, se deveu em grande parte à ausência de vínculos estabelecidos entre os homens e principalmente à ausência de uma linguagem suficiente para comunicar aos outros membros da espécie as descobertas que porventura fossem feitas. É o que se verifica na sequência do texto, onde o autor escreve:

Concluamos que, estando nas florestas, sem trabalho, sem palavra, sem domicilio, sem guerra, e sem laços (...) o homem selvagem, sujeito a poucas paixões, e bastando

de Buffon e esclarece as suas próprias. Já no que diz respeito à concordância com Condillac contra Buffon escreve GOLDSCHMIDT: "En acceptant (contre Buffon) la continuité entre l'entendement animal et l'entendement humain, Rousseau désarme la critique de Condillac. En accordant à celui-ci que, quant à la formation des idées, ,l'homme ne diffère[...] de la bête que du plus au moins', en rappelant que ,quelques philosophes ont même avancé qu'il y a plus de différence de tel homme à tel homme que de tel homme à tel bête', Rousseau se met en règle avec la science contemporaine (celle de son ami, précisément, et, plus généralement, de l'Encyclopédie) “ GOLDSCHMIDT: 1983, p. 282-283.

8 ROUSSEAU, O.C. III, Discours sur l'inégalité, p. 145.

9 Segundo Ricken : "C'est aussi le langage articulé des signes institutionnels qui confère à l'humanité un dimension historique, inconnue aux animaux, dont l'apprentissage s'arrête et recommence à chaque génération nouvelle. Les hommes par contre, grâce à leur langage, accumulent et transmettent de génération en génération un savoir qui seul permet l'evolution de la société humaine. » RICKEN : 1982, p. 88.

10 ROUSSEAU, OC, III, p. 146. 
a si mesmo, possuía apenas os sentimentos e os conhecimentos próprios desse estado (...) e sua inteligência não se desenvolvia mais que sua vaidade. Se por acaso fizesse alguma descoberta, não conhecendo nem mesmo os próprios filhos, não poderia transmiti-la. A arte perecia com seu inventor. Não havia nem educação, nem progresso, as gerações se multiplicavam inutilmente; e cada um partindo sempre do mesmo ponto, os séculos escoavam em toda a rusticidade dos primeiros tempos; a espécie já era velha, e o homem permanecia ainda criança. ${ }^{11}$

Ao insistir na morosidade desse processo, Rousseau marca a distinção entre seu posicionamento e o de Condillac ${ }^{12}$ que, no Ensaio sobre a origem dos conhecimentos humanos, elabora uma explicação hipotética acerca do surgimento e dos progressos da linguagem de forma bem mais abreviada e rápida do que Rousseau a imagina. $\mathrm{O}$ que se evidencia aqui é a intenção de Rousseau em ressaltar o caráter de independência do homem antes que este estabelecesse qualquer tipo de vínculo com seus semelhantes, marcando assim, a distância existente entre o puro estado de natureza e o estado de sociedade. A contraposição, mas também a filiação às ideias condillaquianas a esse respeito é evidenciada pelo próprio autor do segundo Discurso. Vejamos a passagem que descreve o que acabamos de afirmar e que justifica a investigação e o estabelecimento do contraponto entre o Essai de Condillac e os estudos de Rousseau acerca da linguagem.

Seja-me permitido considerar, por um instante, a confusa origem das línguas. Poderia contentar-me em citar ou repetir aqui as pesquisas que o Senhor Abade de Condillac realizou sobre esse assunto, as quais confirmam inteiramente minhas impressões e talvez me tenham fornecido a primeira ideia. Mas, pela maneira como esse filósofo resolve as dificuldades que cria para si mesmo sobre a origem dos sinais instituídos, mostrando que supõe o mesmo que eu questiono, ou seja, um tipo de sociedade já estabelecida entre os inventores da linguagem, creio, voltando às suas reflexões, dever acrescentar-lhes as minhas, para expor à luz as mesmas dificuldades que convêm ao meu tema. ${ }^{13}$

11 ROUSSEAU, OC, III, p. 159-160.

12 Cf. Starobinski: «Tandis que pour Condillac l'histoire du langage se dévelope en quelques générations, Rousseau allègue les peines inconcevables de l'invention des langues : il rende ainsi plausible l'étalement de la préhistoire (l'état primitif de l'homme non modifié par le travail et la culture) à travers un temps indéfini. II s'écoule 'des milliers de siècles' où l'homme ne connaît ni besoins, ni passions, où il ne possède et ne cherche à transmettre aucune technique. » STAROBINSKI, Jean. "Rousseau et l'origine des langues": Sept essais sur Rousseau. In : Jean Jacques Rousseau : la transparence et l'obstacle. Gallimard, 1971, p. 361.

13 ROUSSEAU, O.C. III, Discours sur l'inégalité, p. 146. Sobre a relação entre os ensaios de Rousseau e Condillac, escreve Jacques Derrida: "Referiéndose a Condillac, a quien reconoce deberle mucho, Rousseau expresa claramente su desacuerdo en cuanto al enfoque adoptado por el Ensaio sobre el origen de los conocimientos humanos. En efecto, Condillac parece situar-se ante la sociedad constituida $-y$ creada por Dios - en el momento en que plantea la cuestión del lenguaje, de su génesis y de su sistema, de las relaciones entre signos naturales y signos instituidos, etcétera. En cambio Rousseau aspira a explicar el surgimiento mismo de la convención, es decir, según cree, cómo surgen a la vez la sociedad y el lenguaje a partir del 'puro estado natural'. Para lograrlo debe entonces poner entre paréntesis todo lo que Condillac 
Apesar do respeito pelo autor do Ensaio sobre a origem dos conhecimentos humanos, Rousseau deixa clara sua posição e ressalta que o problema aí encontrado é justamente o fato de Condillac supor em seu Ensaio uma espécie de sociedade já estabelecida entre os inventores da primeira língua. A crítica de Rousseau a Condillac sobre as condições do surgimento da linguagem nos parece semelhante àquela realizada por ele, com relação a Hobbes no que concerne às características atribuídas ao homem natural, ou seja: Rousseau pretende que lhes falta radicalidade ${ }^{14}$. É importante explicitar aqui em que sentido estamos empregando o termo radicalidade. Nos parece que, ao afirmar que Condillac dá por suposto o que ele mesmo (Rousseau) questiona, o genebrino estaria indicando que o abade não recuara suficientemente a ponto de explicar as condições prévias para que se desse a emergência de uma linguagem artificial. Ele critica justamente a existência do que Condillac supõe como axioma fundador de sua teoria, ou seja: a proto-comunidade estabelecida entre duas crianças pós-diluvianas ou a sociedade familiar desde sempre reunida. ${ }^{15}$ Rousseau dirá que seu dever seria "cavar até a raiz"16 para tentar extirpar antigos preconceitos arraigados, tais como aqueles que supunham a sociedade familiar desde sempre reunida ou a existência de uma linguagem adâmica original. Rousseau procura explicitar quais paixões ou necessidades levaram homens isolados e independentes a buscarem os meios de exprimir seus pensamentos, sentimentos e intenções. Tais condições

da por supuesto, y eso es, justamente, lo que pretende hacer". DERRIDA, Jacques. "La linguística de Rousseau”. In: Presencia de Rousseau. Tradução de José Sazbón. Buenos Aires: Ediciones Nueva Vision, 1972 , p. 26.

14 No segundo Discurso Rousseau insiste que a raiz do erro cometido pelos demais autores - e aqui a referência é à noção das línguas familiares elaborada por Condillac - é de transportar para o estado de natureza características próprias do estado de sociedade. Ver: ROUSSEAU, O.C. III, Discours sur l'inégalité, p. 146.

$15 \mathrm{Na}$ segunda parte do Ensaio sobre a origem dos conhecimentos humanos, Condillac prevendo e tentando se defender das críticas que adviriam ao seu livro em função da suposição do estabelecimento de uma linguagem puramente humana, sem recurso à iluminação divina da língua adâmica, supõe que duas crianças de sexos distintos perdidas no deserto após o dilúvio tenham instituído uma língua através de meios naturais, ou seja sem a intervenção divina: «Adam et Eve ne durent pas à l'expérience l'exercice des opérations de leur âme; et en sortant des mains de Dieu, ils furent, par un secours extraordinaire, en état de réflechir et de se communiquer leurs pensées. Mais je suppose que quelque temps après le déluge, deux enfants de l'un et de l'autre sexe aient été égarés dans des déserts avant qu'ils connussent l'usage d'aucun signe. J'y suis autorisé par le fait que j'ai rapporté. Qui sait même s'il n'y a pas quelque peuple qui ne doive son origine qu'à un pareil événement? Qu'on me permette d'en faire la suppositon, la question est de savoir comment cette nation naissante s'est fait une langue. » (Essai: 1998, p. 161.) E em nota de pé de página - após aludir à teoria de Warburton em seu Essai sur les hiéroglyphes - Condillac justifica sua própria hipótese da seguinte maneira: «Si je suppose deux enfants dans la nécessite d'immaginer jusqu'aux premiers signes du langage, c'est parce que j'ai cru qu'il ne suffisait pas pour un philosophe de dire qu'une chose a été faite par des voies extraordinaires, mais qu'il était de son devoir d'expliquer comment elle aurait pu se faire par des moyens naturels. » CONDILLAC : 1998, p. 161.

16 Ver ROUSSEAU, Segundo Discurso, OC, III, p. 160. 
seriam exatamente aquelas que puderam emergir de um "verdadeiro estado de natureza" contrárias a uma pretensa repetição de características desenvolvidas em sociedade. Condillac ao tratar da linguagem, assim como Hobbes ao abordar as características inerentes a natureza humana, teria ficado a meio caminho, na superfície da análise. Isto é, faltou "escavar mais fundo", dito de outro modo, faltou "radicalidade" na sua análise.

Há que se ressaltar aqui as profundas divergências apresentadas por Rousseau no que diz respeito à sociabilidade natural que contrariam a longa tradição que remonta a Aristóteles e que são apresentadas com o auxílio das descrições hipotéticas do Estado de Natureza elaboradas por ele no segundo Discurso. Sobre essa questão importa ler as páginas sobre o Entendimento e Linguagem presentes no livro Anthropologie et Politique: Les principes du système de Rousseau, de Goldschmidt, onde o autor afirma que "a intenção crítica face à questão do direito natural" que permeia todo o segundo Discurso "junta-se aqui a uma tese complexa, aceita ao mesmo tempo pelos jus naturalistas e pelos philosophes, onde se combinam ideias de sociabilidade, de razão e subsidiariamente aquelas de linguagem e de civilização." Ainda segundo o autor, "esta tese, de origem aristotélica e estoicista, define o homem como um ser sociável e racional; ela é reafirmada por Grotius, Cumberland, Pufendorf, Burlamaqui; e é aceita por Diderot, Condillac e a Enciclopédia"17.

Sobre o tipo de dificuldades percebidas por Rousseau no que concerne ao surgimento das línguas, e mencionadas na passagem do segundo Discurso, acima citada, ele esclarece: "a primeira que se apresenta é imaginar como elas (as línguas) se tornaram necessárias; pois, os homens não tendo nenhuma comunicação entre si, não se concebe a necessidade dessa invenção, nem sua possibilidade(...)"18. Nesse estado puro de natureza, suposto por Rousseau, onde o homem é descrito como um ser isolado sem relação com seus semelhantes, nem mesmo reconhecendo-os enquanto tal, é difícil conceber a maneira como se tornaram necessárias estas primeiras instituições humanas.

Após enfatizar as dificuldades inerentes a essa condição, o autor escreve: "Suponhamos essa primeira dificuldade superada; transponhamos por um momento o imenso espaço que sem dúvida existiu entre o estado de natureza puro e a necessidade das línguas; e procuremos, supondo-as necessárias, como puderam elas começar a estabelecer-se". ${ }^{19}$ Outra dificuldade se apresenta, que segundo Rousseau seria "ainda maior do que a precedente". Trata-se de saber 
o que foi mais necessário, se "a palavra para aprender a pensar" ou "saber pensar para encontrar a arte da palavra" 20 .

"Quaisquer que sejam estas origens", insiste o autor, "vê-se, pelo menos o pouco cuidado que tomou a natureza em aproximar os homens" e em "facilitar-lhes o uso da palavra". ${ }^{21}$ Ao negarem a concepção das ideias inatas bem como a ideia da existência de uma língua mãe a partir da qual derivar-seiam as demais línguas históricas ${ }^{22}$ tanto Rousseau quanto Condillac vêem-se na necessidade de explicar, - ou como no caso de Rousseau, em salientar as dificuldades inerentes a este processo de geração - esses complexos primórdios e os necessários encadeamentos entre o surgimento das ideias e a constituição da linguagem. Ambos farão uso da hipótese de uma linguagem natural, puramente instintiva, pouco distinta da linguagem animal, mas principalmente para Rousseau, bastante diversa das línguas instituídas.

A primeira linguagem do homem, a mais universal, a mais enérgica, a única de que precisou antes de dever persuadir homens reunidos, foi o grito da natureza. Como esse grito era arrancado apenas de uma espécie de instinto nas ocasiões mais prementes para implorar socorro quando de grandes perigos, ou alívio nas dores violentas, ele não era de grande utilidade ao curso habitual da vida, quando imperam os sentimentos mais moderados. ${ }^{23}$

Essa primeira linguagem, que Rousseau denomina 'natural', composta basicamente de gritos puramente instintivos e de gestos, era a única disponível antes de os homens estabelecerem relações mais permanentes. $\mathrm{O}$ fato é que Condillac faz derivar imediatamente dessa linguagem natural nascida das

20 ROUSSEAU, O.C. III, Discours sur l'inégalité, p. 147.

21 ROUSSEAU, O.C. III, Discours sur l'inégalité, p. 151.

$22 \mathrm{Na}$ verdade, Condillac não nega, ou ao menos não nega formalmente a existência das ideias inatas e da língua Adâmica. No primeiro Capítulo do Essai ele escreve: «L'âme peut donc absolument, sans le secours des sens, acquérir des connaissances. Avant le péché, elle était dans un système tout différent de celui où elle se trouve aujourd'hui. Exempte d'ignorance et de concupiscence, elle commandait à ses sens, en suspendait l'action, et la modifiait à son gré. Elle avait donc des idées antérieures à l'usage des sens. Mais les choses ont bien changé par sa désobéissance. Dieu lui a ôté tout cet empire : elle est devenue aussi dépendante des sens que s'ils étaient la cause physique de ce qu'ils ne font qu'occasionner et qu'ils lui transmettent. De là l'ignorance et la conscupiscence. C'est cet état de l'âme que je me propose d'étudier, le seul qui puisse être l'objet de la philosophie puisque c'est le seul que l'expérience fait connaître. "( CONDILLAC : 1998 , p. 34). «Ainsi, quand je dirai que nous n'avons point d'idées qui ne nous viennent des sens, il faut bien se souvenir que je ne parle que de l'état où nous sommes depuis le péché. Cette proposition appliquée à l'amê dans l'état d'innocence, ou après sa séparation du corps, serait tout à fait fausse. Je ne traite pas des connaissances de l'âme dans ces deux états parce que je ne sais raisonner que d'après l'expérience. „CONDILLAC : 1998, p. 35). Entetanto, conforme afirma Bertrand : «De manière emblematique, la référence à la langue adamique joue à contre-emploi : Condillac ne l'utilise que pour indiquer qu'il n'est pas nécessaire de remonter au-delà du Déluge pour expliquer l'origine de la parole.» BERTRAND, Aliénor. "L'origine du langage, entre nature et logique". Préface, In : Condillac et l'Origine du langage. Paris : PUF, 2002, p. 10.

23 ROUSSEAU, OC, III, p. 148. 
necessidades, sem grandes diferenças, a linguagem instituída. Tal derivação é expressa no Essai sur l'origine des connaissances humaines através da teoria dos signos e também em algumas de suas obras ulteriores.

No capítulo IV da primeira parte do Essai o autor distingue três espécies de signos: em primeiro lugar estariam "os signos acidentais, ou os objetos que as circunstâncias particulares ligaram a algumas de nossas ideias e que servem para relembrá-las"; em segundo lugar "os signos naturais, ou os gritos que a natureza estabeleceu para os sentimentos de alegria, de medo, de dor etc...." e, em terceiro lugar, "os signos de instituição, ou aqueles que nós mesmos escolhemos e que têm apenas uma relação arbitrária com nossas ideias" 24 .

Na sequência do Essai Condillac explica como se deu a passagem dos gritos naturais ou do que ele chama de 'linguagem de ação', que seria um composto de gritos e de gestos e pouco distinta da linguagem dos animais, aos sinais instituídos e à formação do entendimento e da linguagem; fazendo derivar esta última das necessidades naturais do homem, sem nenhuma diferença ou corte radical entre esta linguagem instintiva e a linguagem humana articulada e instituída. No Traité des animaux, que será publicado no ano de 1755 ele repetirá que "a linguagem de ação prepara a dos sons articulados". ${ }^{25}$ Cabe ressaltar que o surgimento e o aperfeiçoamento da linguagem só se torna possível em sociedade, pois a passagem dos signos naturais aos signos instituídos, supõe o papel determinante do auditor e não somente do emissor do signo. ${ }^{26}$ Afinal, se o objetivo da fala ou da linguagem é se fazer entender, ao se passar uma mensagem, evidenciar uma intenção ou paixão, o receptor deveria compreender a mensagem.

O texto de Jean Morel intitulado "Les sources du Deuxième Discours", publicado em 1909 nos Annales J.-J. Rousseau é outra fonte que pode ser consultada no que diz respeito especificamente às contribuições de Condillac no que concerne a escrita do Segundo Discurso e, sobretudo, no que se refere às questões linguísticas. Neste Longo artigo de quase oitenta páginas o autor examina em detalhe as inúmeras fontes presentes na escrita do Discurso sobre a Desigualdade. Após afirmar já na primeira página, que Diderot e Condillac são, no momento em que Rousseau escreve o Discurso, os escritores mais

24 CONDILLAC : 1998, p. 63.

25 CONDILLAC: 2004, p. 160.

26 Hans AARSLEFF em seu artigo: “Condillac a-t-il trop donné aux signes?" Explica de forma bastante clara essa passagem dos signos naturais aos signos artificiais ou de instituição. AARSLEFF, Hans. "Condillac a-t-il trop donné aux signes?" In : Condillac et l'origine du langage. PUF : Paris : 2002. 
ligados a ele, e que mais o influenciaram ${ }^{27}$, desenvolve a partir da página 143 uma análise precisa da influência condilaquiana sobre o genebrino.

Nas quase dezoito páginas seguintes o autor compara as teorias linguísticas e antropológicas dos pensadores examinando às confluências e às peculiaridades de ambos. Partindo da ideia condilaquiana, plenamente aceita por Rousseau, segundo a qual o homem não nasce como um ser racional, mas torna-se racional a partir das experiências propiciadas pelas sensações, Morel ressalta a importância das palavras para a formação do pensamento e da razão ao mostrar a raiz da primeira língua artificial articulada. Trata-se de uma espécie de "linguagem natural instintiva" que aliada à "linguagem de ação", composta de gritos e gestos, auxilia os primeiros homens na construção do artifício linguístico que lhes possibilitará saírem da animalidade e tornaremse homens propriamente. Não nos aprofundaremos aqui nos detalhes mais técnicos da linguagem, da formação das ideias gerais, dos primeiros tempos verbais criados pelos homens, etc., nos contentamos em remeter o leitor ao artigo supracitado.

Sobre essa língua natural ou substrato pré-reflexivo auxiliar, responsável pelos primórdios da reflexão, Condillac, não satisfeito com as explicações fornecidas no Essai, e motivado também pelas críticas apontadas por Rousseau, ${ }^{28}$ empreenderá novas tentativas de precisar tais noções, o que ocorrerá principalmente em sua Grammaire e na Logique, chegando a afirmar nesta última, a existência de uma lógica natura ${ }^{29}$ anterior ao estabelecimento da linguagem. Entretanto, apesar destas tentativas de precisar e aprofundar sua teoria linguística, a postura Condilaquiana manterá certa constância entre seus diversos escritos. ${ }^{30} \mathrm{O}$ fato é que esse estudo das mudanças sofridas na

27 Ver MOREL, J. "Les sources du Deuxième Discours". In: Annales de la Societé J.-J. Rousseau, T. V, 1909, p. 119.

28 Cf. Aliénor Bertrand : «Attentif aux filiations entre les langues historiques, il se garde également de former l'hypothèse d'une langue universelle qui serait la mère de toutes les autres. Dans sa Grammaire, Condillac répond sur un mode dogmatique à Rousseau, en affirmant que ses conjectures sont hypothétiques et non historiques, et qu'elles ont pour unique but de figurer les conditions de l'emergence du langage des sons articulés. ». BERTRAND, Aliénor. "L'origine du langage, entre nature et logique". Préface, In : Condillac et l'Origine du langage. Paris : PUF, 2002, p. 10-11. Eis a nota remetendo à Grammaire, citada por Aliénor Bertrand: «Voilà sans doute à quoi M. Rousseau n'a pas faite attention. (...) je suppose seulement que les hommes ont eu des besoins, et qu'en conséquence, ils ont observé, non les propriétés des choses, mais les rapports sensibles des choses à eux, et ils les ont observés, parce qu'ils les sentaient, et qu'ils ne pouvaient pas ne pas le sentir. (...) Tous cela ne damandait que cette portion de métaphysique qui est en nous même avant que nous sachions parler, et que les besoins développent dans les enfants 》 (Grammaire, Oeuvres philosophiques, t, II, I, 2, p. 433 apud : BERTRAND : 2002, p.10.)

29 Cf. Bertrand. Préface: "L'origine du langage, entre nature et logique” BERTRAND: 2002 p. 8-9.

30 Cf. Robins : «La thèorie de Condillac sur l'évolution du langage est présentée dans la seconde partie de son Essai sur l'origine des connaissances humaines (1746) ; elle est également discutée dans certains ouvrages ultérieurs, la Grammaire (1775), la Logique (1780) et la Langue des calculs (publié en 1798). En général, son traitement du sujet est relativement constant, même si certaines différences entre les ouvrages 
teoria da linguagem de Condillac em suas obras mais maduras, tais como a Grammaire e a Logique - que mereceriam uma investigação mais aprofundada - ultrapassa o objetivo da análise prevista para esse trabalho, mesmo porque, tendo sido publicadas respectivamente nos anos de 1775 e 1780, não poderiam ter influído na construção da teoria linguística Rousseauniana pelo simples fato de que Rousseau morre no ano de 1778.

Ainda no tocante à questão da 'linguagem natural', e principalmente no que concerne à teoria de Condillac, cabe lembrar conforme Bertrand, que "ela somente poderia ser qualificada de 'linguagem' por extensão"; ela é utilizada de forma imprópria "para designar o conjunto dos elementos inatos permitindo à comunicação de se instaurar. Em sentido estrito, somente a linguagem de ação e a linguagem dos sons articulados podem ser consideradas como as espécies de linguagem que pertencem verdadeiramente à categoria das artes" 31 . Para Rousseau também, esta linguagem somente poderia ser chamada como tal, de modo impróprio, dado que ela será modificada desde seus primórdios pelas condições particulares das línguas instituídas. Mesmo os gritos naturais, mudariam, segundo Rousseau, em função do clima ou mesmo do tipo de fauna presente em cada região, dado que, muitas das primeiras palavras e nomes proviriam da imitação dos gritos dos animais que habitam as diferentes partes do globo e que ajudariam na constituição das diversas onomatopéias ${ }^{32}$ que estão na origem das línguas instituídas.

Rousseau insiste no tempo e nas dificuldades que precisaram ser vencidas para que se pudesse aperfeiçoar a linguagem, desenvolver as ideias abstratas, as noções de números, verbos, partículas, sintaxe e "formar toda a lógica do discurso". ${ }^{33}$ E resolve a situação pela negativa, abandonando-a, e deixando a questão acerca dessa aporia insolúvel em aberto. Vejamos: "Quanto a mim, assustado com as dificuldades que se multiplicam e convencido da impossibilidade quase comprovada de que as línguas tenham podido se estabelecer por meios puramente humanos, deixo a quem queira empreender a discussão desse difícil problema: o qual foi o mais necessário, à sociedade

mentionées ont été relevées par Auroux (1979:30-1). » ROBINS, R.H. « Condillac et l'origine du langage». In : Condillac et les Problèmes du Langage. Textes Recueillis par Jean SGARD. Genève-Paris : Editions Slatkine, 1982 , p. 97.

31 BERTRAND : 2002, p. 121.

32 Sobre o caráter onomatopéico das primeiras línguas Condillac já havia escrito em seu Essai : «(...) les premiers noms des animaux en imitèrent vraisemblablement le cri: remarque qui convient également à ceux qui furent donnés aux vents, aux rivières et à tout ce qui fait quelque bruit. » CONDILLAC : 1998, p. 171.

33 ROUSSEAU, O.C. III, Discours sur l'inégalité, p. 151. 
já formada, quando da instituição das línguas ou das línguas já inventadas, quando do estabelecimento da sociedade". ${ }^{34}$

Cabe ressaltar aqui a importância e as implicações políticas e religiosas que permeiam o debate acerca do surgimento da linguagem, ocorridas a partir desta época e que continuaram a repercutir até a época da Revolução Francesa e a partir daí espalhando-se pelo mundo principalmente no tocante ao surgimento das primeiras instituições humanas e à dessacralização da ordem social. Por isso explica-se a precaução de Condillac em afirmar que suas pesquisas são puramente hipotéticas e só dizem respeito ao tipo de linguagem que pode ter sido produzida pelos homens após o dilúvio. Desta forma, Condillac pretende se isentar de qualquer tipo de acusação de heresia, no sentido de que, esta língua instituída contraria os dogmas da revelação cristã e da língua adâmica transmitida diretamente por Deus. No entanto, apesar das precauções tomadas, Condillac não deixará de ser considerado um dos inimigos mais virulentos da religião cristã em função de sua teoria materialista acerca do surgimento das instituições humanas ${ }^{35}$. Conforme salienta Ricken: "Toda teoria sobre a origem da linguagem implica de alguma maneira uma teoria sobre a origem da sociedade, ao menos no que diz respeito à preexistência ou não da sociedade à linguagem; e também no que diz respeito ao tipo de ser humano que existia no ponto de partida da história da sociedade." ${ }^{36}$

Ainda seguindo o comentador: "um dos primeiros a tirar consequências políticas desta hipótese de a sociedade, a linguagem e o pensamento serem produtos da história, foi justamente Rousseau, com sua interpretação radicalizada da comunicação social exposta no Discurso sobre a origem da desigualdade (1756)", e em seu Ensaio sobre a origem das línguas, inspirado pela hipótese da origem da linguagem desenvolvida no Essai sur l'origine des connaissances humaines "Rousseau atribui à linguagem um papel essencial

34 ROUSSEAU, O.C. III, Discours sur l'inégalité, p. 151.

35 Cf. Ricken: «La théorie linguistique de Condillac n'échappe pas au jugement de Bonald et de Maistre. Pour celui-ci l'hypothèse condillacienne de l'origine commune de la pensée et du langage aurait matérialisé l'origine de nos idées et ainsi dégradé la nature spirituelle de l'homme. Bonnald lui aussi accuse la théorie linguistique de Condillac d'avoir véhiculé une conception de l'homme et de la société qui aurait favorisé le materialisme et le bouleversement de l'ordre naturel de la societé. (...) La théorie sensualiste du langage y est donc pour quelque chose si ce détestable Condillac, ainsi nommé par de Maistre dans ne lettre à Bonnald, aparaît comme le plus coupable des conjurés modernes. » RICKEN, Ulrich. « Condillac et l'origine du langage ». In : Condillac et les Problèmes du Langage. Textes Recueillis par Jean SGARD. GenèveParis : Editions Slatkine, 1982, p. 75. Ver também: RICKEN, U. "Etienne Bonnot de Condillac : lluminismo como antropologia sensorialista e filosofia da linguagem”. In: Filósofos do século XVIII: uma introdução. Tradução de Dankwart Bernsmüller. São Leopoldo: Editora UNISINOS, 2007.

36 RICKEN: 1982, p. 81. 
na origem e na evolução da sociedade e mesmo do gênero humano, assim como na origem e manutenção da desigualdade social" 37 .

Realmente, o uso da linguagem possui papel determinante na constituição das sociedades. No Ensaio sobre a origem das línguas Rousseau responderá à questão exposta, e deixada em aberto no segundo Discurso, - qual teria sido mais necessária, se a linguagem para a formação da sociedade ou a sociedade para a instituição da linguagem - afirmando ter sido a linguagem a primeira instituição social ${ }^{38}$. Entretanto, neste escrito a distância com relação ao sensualismo condillaquiano aparece de forma nítida. Nele Rousseau afirma claramente que a palavra deriva das paixões morais e não das necessidades, tal como afirmara Condillac em seu Ensaio ${ }^{39}$. Este período da história da humanidade, no qual se deu o surgimento da palavra, fruto de um relacionamento mais estreito entre os homens, é localizado por Rousseau na 'idade das cabanas' ou no segundo estado de natureza, aquele que antecede imediatamente o estabelecimento da propriedade e do contrato.

Apesar das divergências, Rousseau aceita a ideia da existência dos gritos naturais e da linguagem de ação ${ }^{40}$, composta por estes gritos e complementada com gestos. Entretanto, conforme afirmamos anteriormente, tal linguagem seria suficiente apenas para atender às necessidades físicas, mas seria incapaz de dar conta das necessidades oriundas das paixões morais e nascidas do convívio mais estreito entre os homens ou da vida propriamente social ${ }^{41}$. Estas só poderiam ser satisfeitas através do uso da fala ou da linguagem dos sons

37 RICKEN: 1982, p. 82.

38 ROUSSEAU, O.C. V, Essai sur l'origine des langues, p. 375.

39 No verbete Sensualismo do Dictionnaire de Rousseau podemos ler a seguinte afirmação que apresenta justamente a distinção entre os posicionamentos de Rousseau em relação à Condillac : « Le second Discours enretient par moments un dialogue avec Condillac, en particulier sur l'origine sociale du langage. Ce thème se révèle si riche qu'il en garde le développement pour l'Essai sur l'origine des langues, rédigé dès 1756. à cette époque, il s'est déjà séparé du sensualisme condillacien sur un point essentiel : le besoin de s'exprimer naît des passions et non des besoins ». Dictionnaire de Rousseau : 2006, p. 853. Essas distinções são apresentadas de forma inequívoca em resposta a Condillac na Capítulo II do Ensaio sobre a origem das línguas onde Rousseau escreve : "pretende-se que os homens inventaram a palavra para exprimir suas necessidades ; tal opinião me parece insustentável. O efeito natural das primeiras necessidades consistiu em separar os homens e não em aproximá-los." OC, V, p. 380.

40 Cf. Starobinski : «(...) sur bien des aspectes du probème, Rousseau reprend les vues de Condillac, qui les avait lui-même élaborées à partir d'une tradition qui remonte à Platon. Comme Condillac, Rousseau voit le langage naître avec le 'cri de la nature' passer par le geste (langage d'action) et aboutir lentement au langage d'institution. Comme Condillac, comme Maupertuis, Rousseau admet que les désignations concrètes et les onomatopées ont précédé les signes abstraits et les termes conventionnels : la communication s'est d'abord effectuée par les symptômes immédiats de l'émotion, avant de passer par le truchement d'un système des signes médiateurs. L'orignalité de Rousseau aparaît d'une part dans la manière dont il multiplie les oppositions embarrassantes, là où Condillac ménage des transitions aisées ; » STAROBINSKI : 1971, p. 363

41 ROUSSEAU, O.C. V, Essai sur l'origine des langues, p. 377-378. 
articulados. Nesse sentido Rousseau escreverá no Ensaio sobre a origem das linguas:

Inclino-me (...) a pensar que, se sempre conhecêssemos tão só necessidades físicas, bem poderíamos jamais ter falado, e entender-nos-íamos perfeitamente apenas pela linguagem dos gestos. Poderíamos ter estabelecido sociedades, pouco diversas do que são hoje, ou que alcançassem até melhor o seu objetivo. Teríamos podido instituir leis, escolher chefes, inventar artes, estabelecer o comércio e, numa palavra, fazer quase tantas coisas quantas fazemos com o auxílio da palavra. ${ }^{42}$

Fica claramente expressa a distinção e o corte radical entre a linguagem dos gestos, ou mesmo da linguagem de ação, fruto das necessidades físicas, que pode, em certa medida, ser partilhada também pelos animais e a linguagem dos sons articulados ou da voz, (parole) que é "arrancada pelas paixões" Esta linguagem convencional, fruto das paixões morais do homem é o que o diferencia dos demais animais. Tal ideia é expressa claramente no início do primeiro capítulo do Ensaio sobre a origem das línguas, onde Rousseau afirma que "a palavra distingue o homem dentre os animais: a linguagem distingue as nações entre si" ${ }^{44}$ e completada ainda no final do mesmo capítulo onde o autor insiste que "a língua de convenção pertence somente ao homem" e este é o motivo pelo qual o homem progride "tanto no bem quanto no mal, e porque os animais não o fazem"45.

O que se percebe aqui, como Rousseau afirmará também no Emílio, é a profunda ligação entre a ética, a moral e as questões políticas. Para o "cidadão de Genebra", como sabemos, é indesejável e ineficaz tratar isoladamente tais questões. "É preciso estudar a sociedade pelos homens e os homens pela sociedade, quem quiser tratar separadamente a política e a moral nada entenderá de nenhuma das duas" ${ }^{\prime 6}$. Cada sociedade, dependendo de seus costumes, terá uma política especificamente adequada para ela e somente para ela. Dito de outra maneiras, as mudanças políticas, temporalmente condicionadas, interferem na moral, na conduta ética e nas próprias características da linguagem.

Como podemos notar, é a partir das elaborações e das relações vivenciadas na e pela língua de convenção que o homem pode progredir, seja para o bem ou para o mal. A língua sofre as influências do clima e das condições nas quais ela 
nasce e se ressente das mudanças sofridas pelo governo e pelas contingências históricas do povo que a fala. As línguas guardam as particularidades dos povos que as falam e se alteram de acordo com as mudanças ocorridas nos povos falantes. Essa relação intrínseca entre o caráter das línguas e dos povos é apresentada tanto por Condillac quanto por Rousseau, apesar das diferenças que podem aí ser percebidas.

Segundo o abade o caráter do povo, da língua por ele falada e o seu modo de governo estão intimamente relacionados. No capítulo XV da segunda parte do Essai, ao tratar Du Génie des Langues, o autor salienta que "duas coisas concorrem para formar o caráter dos povos: o clima e o governo. O clima confere mais vivacidade ou mais fleuma e dessa maneira dispõe mais a uma forma de governo do que a outra; mas estas disposições se alteram por mil circunstâncias" ${ }^{47}$. Apesar de mencionar o clima como sendo um dos fatores que influi sobre o caráter do povos, Condillac considera que esta primeira influência cede lugar ao caráter do governo e que "o caráter de um povo sofre praticamente as mesmas variações que seu governo e não se fixa enquanto este não tenha assumido uma forma constante". ${ }^{48}$ Por sua vez, o governo, influindo sobre o caráter dos povos, influi também sobre o caráter das línguas, e este será finalmente consolidado de forma mais ou menos estável através do gênio dos grandes escritores. Vejamos:

Assim, o governo influi sobre o caráter dos povos, o caráter dos povos influi sobre
o das línguas. É natural que os homens, sempre apressados pelas necessidades e
agitados por paixões, não falem das coisas sem fazer conhecer o interesse que eles
tomam por elas. É preciso que eles juntem gradualmente às palavras ideias acessórias
que marcam a maneira pela qual eles são por elas afetados e os julgamentos que eles
lhes conferem. É uma observação fácil de fazer, pois não existe quase ninguém cujo
discurso não desvele o verdadeiro caráter, mesmo nos momentos onde ele toma mais
precauções para escondê-lo. É suficiente estudar um homem por algum tempo para
aprender sua linguagem; eu digo sua linguagem, pois cada um tem a sua segundo
suas paixões. ${ }^{49}$

Se, como podemos verificar, o caráter de um particular é facilmente observado através de seu discurso, o caráter dos povos "se mostra ainda mais abertamente que o dos particulares. Uma multidão não saberia agir em concerto para esconder suas paixões. Além disso, nós não imaginaríamos a necessidade de fazer mistério de nossos gostos, quando eles são comuns aos 
nossos compatriotas." Nesse sentido, continua Condillac, "tudo confirma então, que cada língua exprime o caráter do povo que a fala" ${ }^{50}$. Influência decisiva, ao menos para fixar o caráter de um povo em uma determinada língua, são os grandes escritores. Estes lhes conferem uma sólida estabilidade, capaz inclusive de fazer face, segundo o autor, às mudanças ocorridas nos costumes $^{51}$.

Nesse sentido, as regras da moral podem ser apreendidas e percebidas através do estudo e da aprendizagem da língua. Conforme afirma Tiellet, em um dos pouquíssimos trabalhos acadêmicos escritos sobre Condillac no Brasil, "a regra da língua é a regra da moral; o estabelecimento da moralidade pública passa, antes de tudo, pela instância dos saberes que se opera na língua. (...) $\mathrm{O}$ manejo da língua, então, aparece como uma tarefa ética. Estabelecidas as formas básicas das construções arquetípicas do discurso moral e suas zonas individuais de desregramento, cabe ver o andamento social da língua e o que suscita o seu desenvolvimento na história" 52 .

Esta íntima relação entre ética, moral e linguagem, se apresenta de maneira matizada por Condillac que - provavelmente em função de sua notável prudência ${ }^{53}$ - a expõe através de argumentos linguísticos ou de sua teoria do conhecimento. Muitos dos problemas verificados em sociedade têm suas causas atribuídas por ele ao mau uso da linguagem e da maneira como apreendemos na e pela língua, as noções morais. "O que acostuma nosso espírito a essa inexatidão" dirá Condillac, "é a maneira como nos formamos na linguagem" ${ }^{4}$. Conforme Claudine Tiercelin, é em função do fato de fazermos uso da palavra muito tempo antes de atingirmos a idade da razão que cometemos tantos erros $^{55}$. Este acesso tardio à idade da razão e todos os descaminhos que seguimos na tarefa de aprendizagem da língua são os responsáveis, em boa medida, pelos insucessos presenciados em sociedade.

Para Condillac é a "razão que coroa todo o entendimento"; ela é o último degrau a ser atingido no processo de aprendizagem sendo a responsável por

50 CONDILLAC: 1998, p. 259.

51 Cf. Condillac : "(...)/e caractère d'un langue, sur tout s'il est fixé par des écrivains célèbres, ne change pas aussi facilement que les moeurs d'un peuple. » (CONDILLAC: 1998, p. 259.) Nota-se aqui outra diferença substancial entre os pensamentos de Rousseau e Condillac. Enquanto Condillac afirma que a escrita serve para conservar a língua conferindo-lhe perenidade, Rousseau no Essai afirmará que : «L'ecriture, qui semble devoir fixer la langue est précisement ce qui l'altére; elle n'en change pas les mots mais le génie ; elle substitue l'exactitude à l'expression. L'on rend ses sentiments quand on parle et ses idées quand on écrit. » ROUSSEAU, O.C. V, Essai sur l'origine des langues, p. 388.

52 TIELLET : 1995, p. 114.

53 Cf. RICKEN : 1982 , p. 88.

54 CONDILLAC: 1998, p. 273.

55 TIERCELIN : 2002, p. 33. 
nossa boa ou má conduta no plano das ações sociais. Nesse sentido justifica-se a ideia, exposta acima, de que o bom uso da linguagem tem implicações éticas e políticas evidentes. Leiamos nas próprias palavras do autor a ideia exposta ainda na primeira parte do Essai:

De todas as operações que descrevemos, resulta uma que, por assim dizer, coroa todo o entendimento: é a razão. Qualquer ideia que possamos fazer, todo mundo concordará que não é, senão através dela, que podemos nos conduzir sabiamente nas questões civis e fazer progressos na busca da verdade. É preciso concluir então, que ela não é outra coisa senão o conhecimento da maneira como devemos reger as operações de nossa alma ${ }^{56}$.

Rousseau, no livro II do Emílio, designará a razão em termos praticamente idênticos aos utilizados por Condillac. Vejamos: "De todas as faculdades do homem, a razão, que não é por assim dizer senão um composto de todas as outras, é a que se desenvolve com mais dificuldade e mais tardiamente" Cabe ressaltar que as semelhanças percebidas entre as concepções de educação e de construção do conhecimento não param por aqui. Se Condillac, na esteira de Locke, acentua o papel dos sentidos na aquisição das ideias e, consequentemente, acaba por invalidar a teoria das ideias inatas, Rousseau, por sua vez, afirmará em uníssono que nós "nascemos capazes de aprender, mas sem nada saber e nada conhecendo" 58 . Em função da atenção concedida ao processo de construção e de ensino que se opera na e pela língua é que tanto Condillac quanto Rousseau concederão tamanha atenção ao método utilizado para ensinar às crianças - afinal, conforme dirá Condillac, "é na infância que nós somos imbuídos de preconceitos que retardam os progressos dos nossos conhecimentos e que nos fazem mergulhar no erro"59- e alertarão para os perigos de um processo prematuro de ensino que não atente para as especificidades da idade dos alunos nem tampouco para o tipo de conteúdo a ser tratado com estes ${ }^{60}$. Entretanto notamos aqui mais uma diferença importante no papel atribuído à razão. Para Condillac, é somente através dela que podemos agir bem em sociedade, ao passo que, para Rousseau, não é a razão, mas "a consciência (...) o mais esclarecido dos filósofos; e nós não precisamos saber o De Officii de Cícero para sermos homens de bem". ${ }^{61}$

56 CONDILLAC: 1998, p. 96.

57 ROUSSEAU, O.C. IV, Emile, p. 317.

58 ROUSSEAU, O.C. IV, Emile, p. 279.

59 CONDILLAC: 1998, p. 289.

60 CONDILLAC: 1998, p. 121.

61 ROUSSEAU, O.C. IV, Emile, p. 767. 
Seguindo-se este processo lento, mas preciso, de aprendizagem, onde as palavras ensinadas não são meras palavras a serem decoradas, mas vêm sempre acompanhadas de ideias nítidas, talvez não se formem pequenos 'prodígios', mas se evite que estes se tornem, no futuro, verdadeiros pedantes sobrecarregados de palavras vãs e de uma linguagem estéril. "Os primeiros progressos desta educação seriam bem lentos, é verdade", confirma Condillac; e "não veríamos prodígios prematuros de sapiência que se tornam, após alguns anos, prodígios de estupidez; mas veríamos uma razão livre de erros e capaz, por consequência, de se alçar a amplos conhecimentos" ${ }^{62}$. Rousseau, no livro II do Emílio, ressaltando as vantagens de seu próprio método, - que ademais não difere muito do método Condillaquiano - dirá: "É verdade que este método não forma pequenos prodígios e não faz com que os preceptores e os professores brilhem, mas forma homens judiciosos, robustos, sãos de corpo e de entendimento, que, sem se terem feito admirar quando jovens, far-se-ão honrar quando adultos". ${ }^{63}$

Peter Jimack, em artigo no qual trata das influências de Condillac, Buffon e Helvetius na escrita do Emílio, salientará o que diz Condillac acerca da educação das crianças sobre "a maneira como se deve formar o espírito delas é perfeitamente análoga àquela exposta nos três primeiros livros do Emílio" "64, além de lembrar ainda que, a "dita educação negativa", que ocupa os dois primeiros livros da mesma obra "não é outra coisa senão a educação perfeitamente positiva dos sentidos" e que "o estudo sucessivo e metódico de cada sentido, exposto por Rousseau, lembra o método do tratado das sensações de Condillac"65.

Se Rousseau insiste em se separar das concepções sensualistas e em demarcar a distância entre esta e as suas próprias, isso se dá, em grande medida, em função do fato delas se parecerem muito. No entender de Jimack, principalmente no que concerne ao método fundado na observação que podemos encontrar no Emílio, as "diferenças que ele (Rousseau) estabelece entre suas próprias doutrinas e aquelas dos sensualistas restam bem menos numerosas do que as semelhanças" 66 . Tais constatações levam o autor a afirmar que "apesar das invectivas contra os 'philosophes', apesar da Profissão de fé do vigário de Sabóia, apesar do estreito parentesco que o liga a Plutarco e

65 "Les influences de Condillac, Buffon et Helvetius dans l'Emile". In : Annales de la Societé J.-J. Rousseau, 1956-1958, T. XXXIV, p. 108.

66 JIMACK: 1956-1958, p. 107. 
aos antigos, o autor do Emílio se mantém completamente imbuído do espírito filosófico e sensualista de seu século" ${ }^{\text {67 }}$.

Voltemos à questão das línguas e de como estas se relacionam e se alteram de acordo com as mudanças sofridas nos costumes e nos governos. Rousseau no livro II do Emílio irá expor nos seguintes termos a relação entre a língua e os costumes de uma nação: "As cabeças formam-se sobre as linguagens, os pensamentos tomam o aspecto dos idiomas. Só a razão é comum, o espírito em cada língua tem sua forma particular, diferença esta que bem poderia ser em parte a causa ou o efeito dos temperamentos nacionais, e o que parece confirmar esta conjectura é que em todas as nações do mundo a língua segue as vicissitudes dos costumes e se altera ou se conserva com eles" ${ }^{68}$. Seguindo de perto a ideia final da passagem acima, Rousseau, no capítulo XIX do Essai sur l'origine de langues, tomando como exemplo as mudanças verificadas na língua grega em função dos rumos conferidos à sua política lembrará que, "a Grécia sob grilhões perdeu aquele fogo que só anima as almas livres e não encontrou mais, para louvar seus tiranos, o acento com o qual cantara seus heróis" $"$.

Se a dependência entre língua, costumes e Governo é necessária, como Rousseau insistirá em várias de suas obras, a relação entre as línguas e o cli$\mathrm{ma}^{70}$ não deixará de ser analisada por ele. Este (o clima) será considerado pelo autor como um fator ainda mais relevante e decisivo do que havia sido considerado pelo abade. Isso porque, sendo a língua a primeira "instituição social, só às causas naturais" ela "deve sua forma" Rousseau entre as flores e as palavras, lembra que o autor do Ensaio sobre a origem das linguas "se recusa a deduzir a linguagem de uma espécie de sociabilidade muda, à maneira de Condillac", e que "sendo a primeira instituição social e não podendo assim mergulhar suas 'raízes' no solo do social, a língua deve enraizar-se diretamente na natureza”, de maneira que "nenhuma análise puramente 'interna' poderia dar conta da estrutura de uma língua". ${ }^{72}$

67 JIMACK: 1956-1958, p. 137.

68 ROUSSEAU, O.C. IV, Emile, p. 346.

69 ROUSSEAU, O.C. V, Essai sur l'origine des langues, p. 425.

70 No que concerne à influência dos climas sobre a civilização, importa ver o fragmento L'influence des Climats sur la civilisation, que conforme afirma Derathé em nota explicativa do texto da Pléiade, tem relação direta com o capítulo IX do Essai sur l'origine des langues. Fragments Politiques( OC, III, p.529 e seguintes). Nele o autor escreve : “Le climat, le sol, l'air, l'eau, les productions de la terre et de la mer, forment son tempérament, son caractère, déterminent ses gôuts, ses passions, ses travaux, ses actions de toutes espèce. » (OC, III, p. 530. Ainda, segundo Derathé, a teoria dos climas exposta por Rousseau teria provindo da leitura Do espírito das leis de Montesquieu ( OC, III, p. 1533.).

71 ROUSSEAU, O.C. V, Essai sur l'origine des langues, p. 375.

72 PRADO JR, Bento. Jean-Jacques Rousseau entre as flores e as palavras. Bento Prado Jr. Almanaque : Cadernos de Literatura e Ensaio. N, Editora Brasiliense, 1978, p. 26. 
Esta terá sua construção e desenvolvimento, profundamente marcados pelo aspecto geográfico e climático que a envolve. Sem esquecer a influência da fauna de cada região, que ajudará os homens a formarem as onomatopéias que estarão na base das diversas línguas particulares. Dessa maneira, antes mesmo de serem estabelecidas relações propriamente sociais, o clima interferirá no tipo de acento que impregnará as línguas nascentes diferenciando-as das demais e conferindo a cada língua e, consequentemente, a cada povo, uma especificidade sui generis. Esta noção é expressa de maneira veemente em L'origine de la melodie, onde o autor afirma que "nós ignoramos tão completamente o estado natural do homem a ponto de não sabermos nem mesmo se existe um tipo de grito que lhe seja próprio", por outro lado, em função do fato de ser um animal imitador ele "poderá então, de início, imitar os gritos daqueles que lhe cercam, e segundo as diversas espécies que habitam cada rincão(contrée), os homens, antes mesmo de possuírem línguas puderam ter gritos diferentes de um país a outro. Além disso, os órgãos estavam mais ou menos (...) flexíveis segundo a temperatura dos climas, que aí já se apresenta a origem do acento nacional mesmo antes da formação da linguagem" "73. A recusa em admitir qualquer espécie de "língua mãe" original que pudesse homogeneizar o gênero humano é evidente. Rousseau insiste no caráter peculiar de cada povo e na autonomia dos costumes e das linguagens que foram se constituindo em cada rincão do globo. O desenvolvimento do argumento mesológico que já aparece de forma evidente no manuscrito acima citado, será desenvolvido nos capítulos VIII, IX, X e XI do Essai, onde nosso autor afirmará que mesmo as "línguas modernas, centenas de vezes misturadas e refundidas, ainda conservam alguma coisa dessas diferenças". ${ }^{74}$

A profunda dependência percebida entre o caráter das línguas e as transformações operadas nos povos, pelos governos e pelos hábitos sociais é ressaltada por ambos os autores. Tanto o abade quanto Rousseau mencionam o fato de que as línguas, nascidas de um desejo de transparência e instituídas em função do desejo de transmitir ideias e sentimentos, acabam, com o passar do tempo, transformando-se em objeto de mistério e engodo, ou de florilégios excessivos que prejudicam a transparência das mesmas. Nesse sentido, podemos ler no primeiro Discurso:

Antes que a arte polisse nossas maneiras e ensinasse nossas paixões a falarem a linguagem apurada, nossos costumes eram rústicos, mas naturais, e a diferença dos 
procedimentos denunciava, à primeira vista, a dos caracteres. No fundo, a natureza humana não era melhor, mas os homens encontravam sua segurança na facilidade para se penetrarem reciprocamente, e essa vantagem, de cujo valor não temos mais noção, poupava-lhes muitos vícios. ${ }^{75}$

De maneira semelhante Condillac já havia exposto, na segunda parte de seu Essai, a ideia, segundo a qual, a linguagem surge eivada de uma intenção de clareza que na sequência de seu desenvolvimento acaba tornando-se objeto de obscurecimento em função do espírito de facção e em um terceiro momento impregna-se do desejo de embelezamento e de florilégios. De maneira que, segundo o autor,"o que devia sua origem à necessidade" e que "tinha sido inventada para a clareza" foi "convertida em mistérios" e "cultivada em função do ornamento". ${ }^{76}$ Já no capítulo XI, ao tratar da significação das palavras, Condillac havia escrito: "Enfim chegou o tempo de homens que, compondo sua linguagem do jargão de todas as seitas, sustentaram o pró e o contra sobre todos os tipos de matéria - talento que nós admiramos e que talvez admiremos ainda, mas que trataríamos com um soberano desprezo se apreciássemos melhor as coisas"77. Condillac, em referência óbvia aos sofistas e ao caráter ambíguo dos discursos a eles atribuídos, manifesta seu desprezo por este caráter intencionalmente dúbio utilizado na construção dos discursos. Além disso, Condillac partilha também da crítica ao uso, excessivamente florido $^{78}$ da linguagem, devido à sua concomitante falta de precisão ${ }^{79}$.

O abade defende que é possível construir línguas de forma clara e precisa onde as ideias sejam expressas de forma evidente. Esta língua teria de ser feita e apreendida sob o método analítico e deveria ser construída a partir de ideias simples. Mesmo as ideias arquetípicas (archétypes) aquelas de justiça, liberdade etc., deveriam ser compostas de um certo número de ideias simples ${ }^{80}$.

Condillac supõe dois modelos distintos de línguas que expressariam, de maneira diametralmente oposta, o excesso de imaginação ou o de precisão geométrica. Vejamos nas próprias palavras do autor seu pensamento expresso no capítulo XV da segunda parte do Essai:

Seria preciso, a fim de fixar nossas ideias, imaginar duas línguas: uma que conferisse tanto exercício à imaginação que os homens que a falassem divagariam sem cessar e outra que, ao contrário, exercesse tão fortemente a análise que os homens aos quais 
ela fosse natural se conduziriam, até mesmo em seus prazeres, como geômetras que buscam a solução de um problema. Entre estas duas extremidades, nós poderíamos representar todas as línguas possíveis, ver-lhes tomar caracteres diferentes conforme a extremidade da qual se aproximassem, e se compensarem das vantagens que elas perderiam de um lado pelas que ganhariam de outro. A mais perfeita ocuparia o meio e o povo que a falasse seria um povo de grandes homens ${ }^{81}$.

Como podemos perceber, para o abade, não se trata apenas de precisão, há que se atingir um equilíbrio entre a imaginação e a beleza de um lado, e a precisão e a clareza de outro. Ele aposta na justa medida, no meio termo. Labarriére, ao tratar dessa questão alerta para o risco de "cedermos ao imperialismo da razão", o que nos conduziria - como mostrou o abade - a nos comportarmos como geômetras mesmo em nossos prazeres (o que não é desejado) e lembra que, para Condillac, "uma bela língua se mantém como uma boa língua" 82 desde que atinja um meio termo ideal.

Tanto Rousseau quanto Condillac concordam ainda que as línguas primevas possuíam um caráter bastante figurado e impreciso, porém, mais vivo que o das línguas modernas ${ }^{83}$, e que eram dotadas de imagens fortes, mas bastante imperfeitas que possuíam caracteres que as aproximavam muito mais do canto ${ }^{84}$ do que da prosa. Dado o fato de que a esses homens, ainda bastante embrutecidos, era muito mais simples variarem as mesmas palavras segundo diferentes entonações do que inventarem novos vocábulos ${ }^{85}$ Ambos os autores vêem ainda nas línguas grega e romana exemplos marcantes desses primeiros tempos onde os acentos que possuíam mantinham papéis preponderantes. Essas línguas, extremamente acentuadas e de caracter 'público', ${ }^{86}$ próprias para serem utilizadas a "céu aberto", diferiam profundamente das nossas, bem mais simples e indicadas somente aos ambientes fechados e restritos. Vejamos o que diz Condillac ao analisar a prosódia das línguas antigas (grega e romana principalmente):

81 CONDILLAC: 1998, p. 267.

82 LABARRIERE : 1982, p. 108.

83 Cf. CONDILLAC: 1998, p. 199.

84 Condillac escreve no capítulo III da segunda parte do Essai : « Il est constant que les Grecs et les Romains notaient leur déclamation, et qu'ils l'accompagnaient d'um instrument. Elle était donc un vrai chant ». CONDILLAC : 1998, p. 173.

85 Cf. CONDILLAC : 1998, p. 172.

86 Jean-Louis Labarriére em seu artigo "Le génie et le jeu dans l'essai de Condillac", ao analisar este caráter público da línguas antigas em contraposição ao caráter fechado das línguas modernas escreve: «Par opposition aux langues anciennes, que l'on a dit 'ouvertes', l'on pourra dire des modernes qu'elles sont 'fermées', mais il faudrait, bien entendu, préciser et nuancer pour chaque langue. Les langues anciennes portaient au loin, à l'inverse des modernes qui sont plus intimes et qui par là sont moins populaires. 》 LABARRIERE : 1982, p. 112. 
Eu percebo ainda na prosódia dos antigos a razão de um fato que ninguém, creio eu, tenha explicado. Trata-se de saber como os oradores romanos que arengavam na praça pública podiam ser ouvidos por todo o povo. Os sons de nossa voz chegam facilmente às extremidades de uma praça de razoável extensão; toda a dificuldade é de impedir que os confundamos, mas esta dificuldade deve ser menor na proporção que, pelo caráter da prosódia de uma língua, as sílabas de cada palavra se distinguem de maneira mais sensível. No latim, elas diferiam pela qualidade do som, pelo acento que, independentemente do sentido, exigia que a voz se elevasse ou se abaixasse, e pela quantidade ; faltam-nos acentos, nossa língua praticamente não possui quantidade, e muitas de nossas sílabas são mudas. Um romano podia então, se fazer compreender distintamente em uma praça onde um francês não o poderia senão dificilmente ou, talvez, de maneira nenhuma. ${ }^{87}$

Este elogio do caráter público das línguas antigas em contraposição ao caráter privado das nossas é apresentado também por Rousseau, principalmente no último capítulo do Ensaio sobre a origem das línguas, onde, ao tratar da relação existente entre as línguas e os governos, ele salienta, em termos bastante próximos dos utilizados por Condillac, o caráter enfraquecido das línguas modernas, principalmente se comparadas às antigas. Entre os antigos, escreve Rousseau, "era possível fazer-se ouvir na praça pública; falavase o dia inteiro sem dificuldade. Os generais arengavam suas tropas, eram compreendidos e absolutamente não se cansavam." Em contraposição, o genebrino supõe um homem arengando em francês diante do povo de Paris reunido em uma pequena praça: "pode gritar a mais não poder, ouvir-se-ão seus gritos, não se distinguirá nem uma palavra. Heródoto lia sua história aos povos da Grécia reunidos ao ar livre e tudo ressoava com aplausos. Hoje, o acadêmico que lê uma memória, num dia de assembléia pública, mal é ouvido no fundo da sala" $"$.

A diferença entre as posturas de ambos os autores se apresenta, entretanto, no que concerne aos "progressos" posteriores, verificados nas línguas, na medida em que estas se aperfeiçoam. Para o abade, as línguas perdem em sentimento e imaginação, mas por outro lado ganham em precisão e clareza; fato considerado positivo, sobretudo no que diz respeito à construção e à exposição analítica dos conhecimentos. Apesar de admitir que as línguas antigas eram mais vivas e eloquentes, Condillac afirma que a língua francesa compensa esta perda, em função de sua simplicidade e clareza, características que a tornam mais exata, mais própria à grande ligação de ideias e, nesse sentido, superior às línguas grega e romana ${ }^{89}$. Já no entender de Rousseau, 
à medida que a linguagem se "aperfeiçoa" ela "torna-se mais justa e menos apaixonada, substitui os sentimentos pela ideias, não fala mais ao coração, senão à razão. Por isso mesmo, o acento se extingue e a articulação progride; a língua fica mais exata, mais clara, porém mais morosa, mais surda e mais fria" ${ }^{90}$. O que, ao fim e ao cabo, fará com que estas percam toda e qualquer possibilidade de despertar as paixões, motivar ações políticas e a participação efetiva nos assuntos públicos.

É preciso salientar que as concepções de Rousseau acerca da origem, dos progressos e da decadência das línguas e as implicações políticas e morais daí decorrentes, tiveram em Condillac uma fonte substancial de inspiração. É certo que Rousseau se diferencia em muitos e importantes pontos da teoria condilaquiana, sobretudo no que diz respeito ao fato de a palavra ter surgido em função das paixões morais e não das necessidades físicas, assim como, no que concerne aos rumos e aos desdobramentos verificados nas línguas com o passar do tempo. O que para Condillac parece indicar uma evolução, principalmente se forem levadas em consideração a construção dos conhecimentos e as implicações diretas na vida civil dos homens, para Rousseau corresponde a uma nítida decadência, dado que a linguagem perde em capacidade de convencimento e de motivação de ações políticas à medida que ganha em precisão e clareza. $\mathrm{O}$ fato é que, apesar das profundas divergências, sempre se entenderá menos completamente a teoria política e linguística de Rousseau se não tivermos em mente a importância que exerceu a teoria condilaquiana para a construção da teoria político-linguística do cidadão de Genebra.

Entretanto, este autor, que marcou tão profundamente a filosofia das luzes e que contribuiu de forma substancial para a construção das teorias linguísticas de Rousseau e de Diderot ${ }^{91}$ e de tantos outros autores do período - e que estudos recentes revelam ser a verdadeira origem de inúmeras ideias atribuídas a linguistas e antropólogos da atualidade ${ }^{92}$, acabou, por uma série de contingências, ficando um tanto apagado na História da Filosofia, sobretudo no Brasil, onde, até hoje, poucas são as pesquisas sobre ele.

90 ROUSSEAU, OC, V, p. 384.

91 Sobre a instigante relação entre Condillac e Diderot, na impossibilidade de tratar aqui de forma mais detalhada, nos contentamos em citar a ideia de que Condillac serviu de fonte de inspiração para Diderot em muitos dos pontos relacionados ao tema do materialismo e da linguagem. Entretanto, tal afirmação não pode nos fazer supor que Diderot teria se contentado em repetir Condillac, pelo contrário, a leitura das obras e os comentários de especialistas nos mostram que em muitos pontos Diderot teria mesmo radicalizado os temas condillaquianos e avançado em veredas não exploradas por este. Para os que se interessarem em investigar mais a fundo o papel desta 'influência capital' observada na obra de Diderot, fica a sugestão do esclarecedor artigo de BAUDFFIER, ( BAUDFFIER: 1982 p. 133).

92 Cf. ROBINS: 1982, p. 96-100. 


\section{Referências bibliográficas}

ROUSSEAU, Jean Jacques. As Confissões. Tradução de Rachel de Queiroz, São Paulo: Atena Editora, 1936.

, Discurso Sobre a Origem e os Fundamentos da Desigualdade Entre os Homens. Tradução de Iracema Gomes Soares e Maria Cristina Roveri Nagle. Brasília: Editora Universidade de Brasília; São Paulo: Ática, 1989.

, Ensaio Sobre A Origem das Linguas. In: Obras J.J. Rousseau, vol, II. Tradução de Lourdes Santos Machado. Rio de Janeiro - Porto Alegre - São Paulo: Editora Globo, 1962.

Unicamp, 1994.

, Júlia ou a nova Heloísa. Tradução de Fulvia Moretto, Campinas: Hucitec/

ROUSSEAU, Jean Jacques. Oeuvres complètes, I, II, III, IV e V, Paris: Éditions Gallimard, 1964- 1995.

AARSLEFF, Hans. "Condillac a-t-il trop donné aux signes?" Condillac et Wittgenstein) In : Condillac, l'origine du langage. Coordonné par Aliénor Bertrand ; Paris : PUF, 2002.

BERTRAND, Aliénor. Préface : "L'origine du langage, entre nature et logique." In : Condillac, l'origine du langage. Coordonné par Aliénor Bertrand ; Paris : PUF, 2002. , "Le langage naturel, condition logique de l'institution des langues." In :

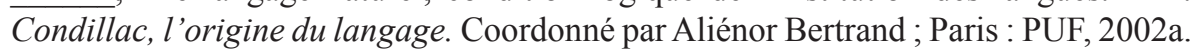
CONDILLAC, Etienne Bonnot de. Essai sur l'origine des connaissances humaines. Paris: ALIVE, 1998.

, Traité des animaux. Presente et annoté par Michel MALHERBE. Paris: VRIN, 2004.

DERRIDA, Jacques. "La Linguistique de Rousseau". In: Presencia de Rousseau. pp. 21- 45. tradução de José Sazbón. Buenos Aires: Ediciones Nueva Vision, 1972.

GOLDSCHMIDT, Vitor. Anthropologie et Politique : les principes du système de Rousseau. Paris : VRIN, 1983.

JIMACK, P. "Les influences de Condillac, Buffon et Helvetius dans l'Emile". In : Annales de la Societé J.-J.Rousseau, T. XXXIV, 1956-1958.

LABARRIERE, J.L. "Le génie et le jeu dans l'essai de Condillac". In : Condillac et les problèmes du langage. Textes recueillis par Jean SGARD. Genève-Paris : Editions Slatkine, 1982.

MOREL, J. "Les sources du Deuxième Discours". In : Annales de la Societé J.-J. Rousseau, T. V, 1909.

PRADO JR, Bento. "Jean-Jacques Rousseau entre as flores e as palavras", Almanaque: Cadernos de Literatura e Ensaio. Nㄱ, Editora Brasiliense, 1978.

RICKEN, U. "Linguistique et anthropologie chez Condillac". In : Condillac et les problèmes du langage. Textes recueillis par Jean SGARD. Genève-Paris : Editions Slatkine, 1982. 
, "Etienne Bonnot de Condillac : Iluminismo como antropologia sensorialista e filosofia da linguagem". In: Filósofos do século XVIII: uma introdução. Tradução de Dankwart Bernsmüller. São Leopoldo: Editora UNISINOS, 2007.

ROBINS, R.H. "Condillac et l'origine du langage". In : Condillac et les problèmes du langage. Textes recueillis par Jean SGARD. Genève-Paris : Editions Slatkine, 1982.

SGARD, Jean. Condillac et les problèmes du langage : textes recueillis par Jean SGARD. Genève-Paris, Editions Slatkine, 1982.

STAROBINSKI, Jean. Jean-Jacques Rousseau : La transparence et l'obstacle suivi de Sept essais sur Rousseau. Paris : Gallimard, 1971.

TIELLET, Paulo Cézar. Conhecimento e ética em Condillac : o manejo social da língua. Dissertação de mestrado apresentada à UGF - Universidade Gama Filho - RJ em Maio de 1995.

TIERCELIN, Claudine. "Dans quelle mesure le langage peut-il être naturel?" (Condillac, Reid). In : Condillac, l'origine du langage. Coordonné par Aliénor Bertrand ; Paris : PUF, 2002.

TROUSSON, Raymond et HEIGELDINGER, Frédéric (Orgs). Dictionnaire de JeanJacques Rousseau. Paris : HONORÉ CHAMPION, 2006. 